\title{
Precisiones sobre un altar de la iglesia madrileña de las Comendadoras de Santiago
}

\author{
Jesús Ángel SÁNCHEZ RiverA* \\ An altar of the Comendadoras of Santiago (Madrid): \\ some precisions
}

«(...) se ponía a dar vueltas por la iglesia, mirando los estandartes de la Orden de Santiago que hay en las Comendadoras, acercándose a la reja grande para atisbar a las monjas, inspeccionando los altares recargados de exvotos de cera.»

Benito Pérez Galdós, Miau'.

\begin{abstract}
RESUMEN
Analizamos el altar del Santísimo

Sacramento que se localiza en la iglesia de las Comendadoras de Santiago (Madrid), en cuya realización participaron diversos artistas: el arquitecto José Fernández Piedra, el pintor Jacinto Gómez Pastor y, acaso, uno de los hermanos Michel (Roberto y Pedro), o algún escultor de su círculo.

ABSTRACT

We analyse the altar of the Saint Sacrament that it's located in the church of the Comendadoras of Santiago (Madrid), in whose realisation several artists participated: the architect José Fernández Piedra, the painter Jacinto Gómez Pastor and, maybe, one of the Michel brothers (Roberto and Pedro), or some sculptor of his circle.

PALABRAS CLAVE: Comendadoras de Santiago. Monasterio. Madrid. Altar. Arquitectura. Escultura. Pintura. José Fernández Piedra. Jacinto Gómez Pastor. Siglo XVIII. Neoclasicismo.

\author{
KEYWORD: \\ Comendadoras of Sant James. Monastery. \\ Madrid. Altar. Architecture. Sculpture. \\ Painting. José Fernández Piedra. Jacinto \\ Gómez Pastor. 18th century. \\ Neoclassicism.
}

La iglesia conventual de las Comendadoras de Santiago de Madrid pasa por ser uno de los templos barrocos más bellos entre los erigidos en la Villa y Corte du-

* Doctor en Historia del Arte. Universidad Complutense de Madrid.

1 PÉREZ GALDÓS, B.: Miau, Madrid, 1888, cap. 23 (citamos por la edición de: Madrid, Cátedra, 2005, pág. 263). 
rante la segunda mitad del Seiscientos. Como es sabido, su construcción se debió a los hermanos Manuel y José del OImo (1631-1706 y 1638-1702), quienes, después de tres décadas de trabajo, la vieron concluida en septiembre de 1696, fecha en que se inauguró con gran regocijo de la comunidad santiaguista².

A lo largo de la siguiente centuria, el antiguo inmueble de las Comendadoras se vio sometido a un importante proceso de transformación, primero mediante la edificación de una nueva sacristía en su extremo nordeste -la conocida como «sacristía de los Caballeros», levantada por Francisco de Moradillo (h. 17201784) - , seguidamente por diversas intervenciones efectuadas en la parte septentrional adyacente al templo y, más tarde, a través de la erección del gran convento diseñado por Francesco Sabatini $(1721-1797)^{3}$. Resulta indudable que todas estas intervenciones afectaron, en mayor o menor medida, a la fábrica de la iglesia, y de manera especial a los accesos que comunicaban con el convento y a la disposición de varios de los altares primitivos.

Terminada la construcción del proyecto sabatiniano para las viviendas de las religiosas, se hubieron de acometer distintas reformas en el interior de la iglesia. Es entonces cuando se efectuaría la reforma del altar que ahora nos ocupa. Según las cuentas conservadas, en 1783 se abonaron 7.164 reales a José Fernández Piedra, profesor de arquitectura ${ }^{4}$, por la dirección de la obra de un altar, que había sido encargada por la Comendadora Mayor ${ }^{5}$ y el arquitecto Francisco de Moradillo. En concreto, la reforma consistió en la realización de una «mesa de altar a la italiana», sagrario y tabernáculo, además de la talla de una Virgen del Pilar6. Es muy probable que dicho altar sea el que se encuentra frente al comulgatorio de las religiosas. La descripción del documento se ajusta muy bien al estilo de este altar de madera marmorizada, obra poco conocida del neoclasicismo madrileño (fig. 1). Por otra parte, prueba que Moradillo se mantuvo vinculado a las intervenciones efectuadas en la iglesia tras finalizar la construcción del convento bajo la supervisión de Sabatini ${ }^{7}$.

2 Para un mayor conocimiento del proceso constructivo de la iglesia y del convento santiaguista a lo largo del siglo XVII, remitimos a nuestra tesis doctoral: SÁNCHEZ RIVERA, J. Á.: El Real Monasterio de Comendadoras de Santiago el Mayor de Madrid: patrimonio histórico-artístico, vol. 1, Madrid, Universidad Complutense, 2010, págs. 363-394 (tesis doctoral inédita).

3 Vid. Ibid., págs. 395-443.

${ }^{4}$ Quizá se trate del opositor de 1746 para las pensiones de Roma, que, finalmente, no logró, citado por QUINTANA MARTÍNEZ, A.: La arquitectura y los arquitectos en la Real Academia de Bellas Artes de San Fernando (1744-1774), Madrid, Xarait, 1983, pág. 139.

5 Hubo de ser doña Francisca $\mathrm{M}^{\mathrm{a}}$ Montserrat y Cruillas, prelada del monasterio durante buena parte de la segunda mitad del siglo XVIII. Vid. SÁNCHEZ RIVERA, J. Á.: Op. cit., vol. 1, págs. 229-230.

${ }^{6}$ Archivo Histórico Nacional (AHN), Órdenes Militares, Consejo, leg. 3.555 ${ }^{1}$ (signatura antigua). El presupuesto se había hecho el 15 de noviembre del año anterior; AHN, Órdenes Militares, Consejo, leg. $3.555^{2}$ (signatura antigua).

7 También, el 22 de abril de 1779 Moradillo había emitido un dictamen sobre la situación de los enterramientos en las capillas de la entrada $-\mathrm{y}$, al parecer, existió otro de Sabatini-; AHN, Órdenes Militares, Consejo, leg. $3.553^{1}$ (signatura antigua). 


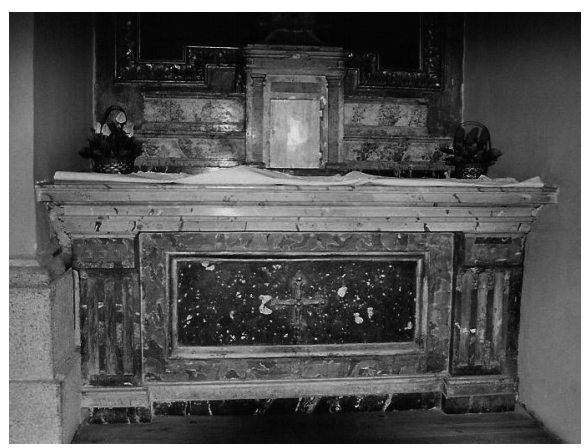

Fig. 1. José Fernández Piedra (?). Altar del Santísimo Sacramento. Iglesia de las Comendadoras de Santiago, Madrid.

Como hemos referido, la mesa del altar, las gradas y el sagrario responden a un diseño neoclásico de gran variedad cromática, materializado en un acabado de la madera a imitación de jaspes (ocres, anaranjados, rojizos, granates, azules, verdes y negros, además de tener algún adorno dorado). El frente ofrece una cruz griega flordelisada en el centro, enmarcada por una moldura, dorada como dicha cruz; está flanqueado por sendas pilastrillas, con triglifos en correspondencia con tres tachuelas doradas; todas las superficies se articulan por medio de molduras rectas. Sobre el tablero, un sagrario cúbico con pilastrillas y molduras, además de dos pares de gradas a cada lado del mismo; en origen lo remataba un Agnus Dei sobre peana dorada — subrayando el sentido eucarístico de la obra ${ }^{8}$, hoy desaparecido y sustituido por una imagen industrial de la Virgen del Carmen.

Preside el altar un bello lienzo de Jacinto Gómez Pastor (1744-1812), representación de la Apoteosis de la Eucaristía (fig. 2) $)^{9}$. Se trata de una pintura alegórica

${ }^{8}$ AHN, Órdenes Militares, leg. 7.366, «Lista de los efectos que hay en la Real Yglesia y Sacristía...», sin foliar.

9 En la ficha técnica de la obra, que sigue a continuación, incluimos: signatura (del catálogo de nuestra tesis doctoral), autoría, datación, materiales y técnicas, dimensiones, inscripciones, estado de conservación, emplazamiento, fuentes y bibliografía.

Pc-178. Jacinto Gómez Pastor. Hacia 1783. Óleo sobre lienzo. Aprox. 300 x $180 \mathrm{~cm}$. Marco coetáneo de madera moldurada, tallada y dorada, con diseño mixtilíneo, de aprox. $340 \times 220 \mathrm{~cm}$. Se pueden distinguir algunas letras en el libro (en color rojo, «A»y «D»; el resto en negro), que Arnaiz refirió como «Amar a Dios sobre todas las cosas». Estado de conservación: bueno; únicamente se hace necesaria una limpieza de la superficie y, tal vez, una restauración del marco. Emplazamiento: preside un altar situado en la parte occidental de la iglesia, frente a la reja del comulgatorio de las religiosas (ubicación original). Fuentes: AHN, Órdenes Militares, leg. 7.366, «Lista de los efectos que hay en la Real Yglesia y Sacristía...", sin foliar. Bibl.: OSSORIO Y BERNARD, M.: Galería biográfica de artistas españoles del siglo XIX, Madrid, 1883-1884, pág. 373; VIÑAZA, C. de la: Adiciones al Diccionario Histórico de los más ilustres Profesores de las Bellas Artes en España de D. Juan Agustín Ceán Bermúdez, Madrid, Tipografía de los Huérfanos, 1889-1894, tomo II (1889), pág. 230; TORMO, E.: Las iglesias del antiguo Madrid, 2 fascículos, Madrid, Imprenta de A. Mazo, 1927, § 38 (confunde la autoría); TAMAYO, A.: Las iglesias barrocas madrileñas, Madrid, 1946, pág. 121 (siguiendo a Tormo, confunde la autoría); TOVAR MARTíN, V. (dir.): Inventario artístico de edificios religiosos madrileños de los siglos XVII y XVIII, tomo I, Madrid, Centro Nacional de Información Artística, Arqueológica y Etnológica, 1983, pág. 123 (persiste en la autoría 
del Santísimo Sacramento de la Eucaristía en la Gloria. En el eje central de la composición se representa una custodia con la Sagrada Forma que irradia luz dorada. La sostiene sobre una nube un ángel mancebo, que la sujeta delicada y respetuosamente con un lienzo blanco; esta figura es la única que mira hacia el espectador, recurrente artificio destinado a llamar la atención del fiel e implicarle en la escena. Varios angelotes y cabezas de querubes rodean la custodia, en actitud adoratriz. Por debajo de ellos — ya en la mitad inferior del lienzo-, pero formando parte del grupo, hay dos angelotes más, también gravitando, uno con racimos de uvas y el otro con un haz de espigas de trigo, símbolos inequívocos de la Eucaristía. También en la zona inferior lienzo aparece una bella figura femenina de pie sobre una lápida, vestida a la antigua, con manto y túnica blancos, casco y sandalias; sostiene un cáliz en su mano izquierda y lleva al pecho la mano contraria; a sus pies, dos angelotes, uno sentado con un libro abierto (y en él escrito el primer mandamiento de la Ley mosaica, «Amar a Dios sobre todas las cosas») y el otro de pie sujetando dos tablas. Como explicaremos a continuación, ésta es la representación alegórica de la Fe católica. Más allá se extiende un paisaje con algunos árboles y montañas, que perfilan una línea de horizonte baja.

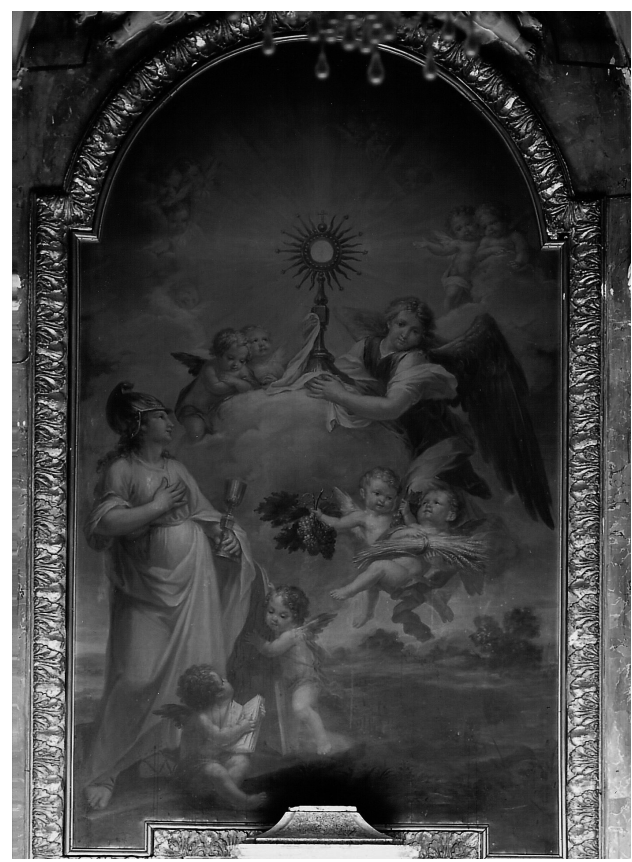

Fig. 2. Jacinto Gómez Pastor. Apoteosis de la Eucaristía [PC-178]. Lienzo del altar del Santísimo Sacramento en la iglesia de las Comendadoras de Santiago.

equivocada); CAMÓN AZNAR, J. et alii: Arte español del siglo XVIII, col. Summa Artis. Historia General del Arte, vol. XXVII, Madrid, Espasa-Calpe, 1984, pág. 156; MORALES Y MARÍN, J. L.: Pintura en España, 1750-1808, Madrid, Cátedra, 1994, pág. 179; ARNAIZ, J. M.: «Sobre Goya y algunos pintores de su entorno", Anuario del Departamento de Historia y Teoría del Arte, vol. XI (1999), pág. 281, fig. 34. 
Queremos llamar la atención sobre la elección de este asunto para presidir el altar donde se encuentra. No resulta casual que dicho altar se dedicase al Sacramento de la Eucaristía. Precisamente, frente a él se encuentra la reja por donde las religiosas solían recibir la Sagrada Forma durante la misa de manos del sacerdote; de hecho, el altar ya estaba consagrado para esta función litúrgica a fines del siglo XVII, cuando se inauguró el templo ${ }^{10}$. En este caso, el decoro, la adecuación de lo representado al lugar en donde se ubica, resulta perfecto y sumamente calculado. Incluso la composición misma se ajusta al lugar, pues nuestra mirada nos lleva desde el lado izquierdo hacia el elemento más importante, la custodia, para terminar reposando en el paisaje del fondo; exactamente es éste el recorrido que ha de hacer el fiel al contemplar la obra, accediendo al altar por su izquierda.

El gusto neoclásico por la Antigüedad se evidencia, especialmente, en la figura femenina, que evoca a las estatuas clásicas (p. ej., ciertas matronas y diosas romanas); el casco que corona su cabeza responde asimismo a ese gusto arqueológico. De cualquier modo, el grupo formado por esta figura y los dos angelillos la acompañan es una alegoría de la Fe católica inspirada en la Iconología de Cesare Ripa (fig. 3). Así explica el escritor cómo se ha de representar:

«Mujer vestida de blanco que se apoya la diestra sobre el pecho, mientras sostiene un Cáliz con la siniestra (...).

Ésta pues, se pondrá vestida de blanco y de rostro bello, haciéndose porque el color blanco muestra semejanza con la luz, cosa pura y perfecta por naturaleza (...).

Muestra además la blancura del vestido, que esa virtud no se adquiere introduciendo el alma en ciencias y saberes, del mismo modo que el color blanco que se logra en los tejidos no se produce con colores materiales, sino sólo purificando los paños y las telas de las esencias de los demás colores (...).

La mano que mantiene sobre el pecho muestra cómo en el interior de su corazón la viva y verdadera Fe se contiene, haciéndonos acreedores al premio por el hecho de poseerla (...).

Con la otra mano sostiene por fin el Cáliz, símbolo de la Fe, en el que se fundan todas nuestras esperanzas y la verdadera finalidad de nuestros deseos $(\ldots)^{11}$.

Seguidamente, el de Perugia añade que la Fe católica ha de ser:

«Mujer vestida de blanco, que lleva un yelmo que la cabeza le cubre. Sostendrá (...) en la siniestra las tablas de la vieja Ley, junto a un libro abierto (...).

10 SÁNCHEZ RIVERA, J. Á.: Op. cit., vol. 1, pág. 387.

11 RIPA, C.: Iconología, Siena, 1613 (5aㅡ edición; la edición princeps es de: Roma, 1593); hemos manejado la edición moderna, traducida al español, de: Madrid, Akal, 2002, tomo I, págs. 402-403. 
Siendo esta virtud una de las llamadas Teologales, lleva en la cabeza el Yelmo, simbolizándose así que para poseer verdadera Fe es preciso mantener protegido el ingenio contra armas enemigas, que no son otras que los razonamientos naturales de los filósofos y las sofísticas alegaciones de los Heréticos y los malos Cristianos, manteniendo nuestra mente firme y segura en los divinos mandamientos y doctrinas evangélicas (...).

El libro que sostiene, junto a las tablas de Moisés, representan reunidos el Viejo y el Nuevo Testamento, compendio principalísimo de lo que debemos creer, los mandamientos de Cristo Nuestro Señor y los que incluye la Ley Vieja $(\ldots)^{12}$.

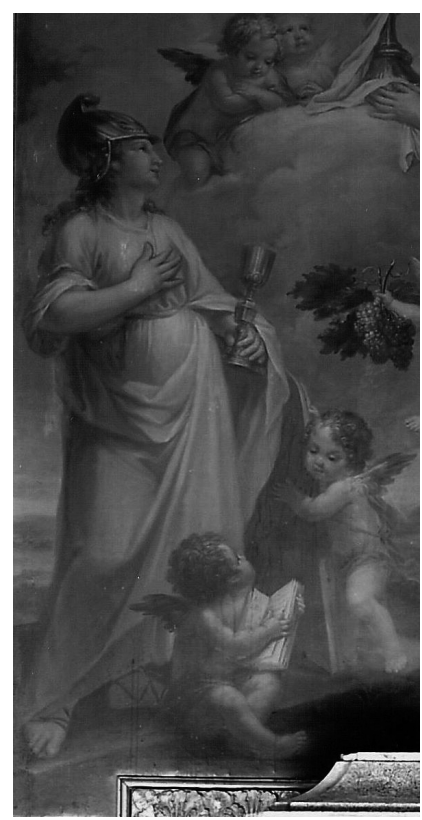

Fig. 3. La Fe católica, detalle de la Apoteosis de la Eucaristía de Gómez Pastor.

En definitiva, a la luz de las explicaciones proporcionadas por Ripa, el mensaje de la obra resulta muy claro: la exaltación del Santísimo Sacramento de la Eucaristía, creencia fundamental de la Fe católica. No es difícil imaginar, por otra parte, que los círculos eclesiásticos buscaran promover y reafirmar el culto a la Eucaristía ante los ataques de la filosofía ilustrada — seguramente, la pintura se hizo a fines del siglo XVIII- En aquel contexto, muy a propósito parecerían las palabras del tratadista perugino que acabamos de leer: «para poseer verdadera Fe es preciso mantener protegido el ingenio contra armas enemigas, que no son otras que los razonamientos naturales de los filósofos y las sofísticas alegaciones de los Heréticos y los malos Cristianos, manteniendo nuestra mente firme y segura en los divinos mandamientos y doctrinas evangélicas».

12 Ibid., tomo I, pág. 404. 
En nuestra opinión, el artista pudo utilizar una de las estampas que ilustran alguna de las numerosas ediciones antiguas de la obra de Ripa (se conocen al menos 13 ediciones italianas, 7 francesas, 4 alemanas y 6 holandesas) ${ }^{13}$. Tampoco habría que descartar el influjo de otras obras que se publicaron durante el siglo XVIII siguiendo el ejemplo del célebre tratado —el gusto de la época fue muy proclive a las representaciones alegóricas-, como la Iconologiae iniciada por Gravelot y continuada por Cochin y Gaucher (París, 1791) ${ }^{14}$; aunque ninguna de sus ilustraciones represente la alegoría de la Fe católica a la manera del italiano ${ }^{15}$, ciertas figuras, por ejemplo la de La Prudencia, recuerda a la que ahora analizamos ${ }^{16}$.

Por otro lado, la custodia y el cáliz que aquí aparecen responden a ciertos modelos neoclásicos del momento. El sol de la custodia es una interpretación neoclásica de piezas del siglo XVII, con rayos flameantes y rectos terminados en bolas alternos, marco perlado, orbe y cruz de remate; el astil se inicia con bola, toro y cuerpo periforme. Sin embargo, el nudo ochavado de ésta y del cáliz se corresponde con modelos de comienzos del XVIII ${ }^{17}$.

Estos objetos están ejecutados con primor, como también lo están las uvas o las espigas; el pintor muestra su destreza en el género de la naturaleza muerta. Las figuras de los angelotes poseen cierta gracia, destacando en candor infantil de algunos de ellos. Creemos que una limpieza del cuadro sacaría a la luz las sutilezas de las veladuras, en particular de las carnaciones; advertimos agradables tonalidades bajo la suciedad acumulada que han de ser recuperadas para el disfrute completo de una obra excelente.

Ossorio ya asignó este lienzo a Jacinto Gómez Pastor, pintor probablemente formado en las obras del Real Sitio de la Granja de San Ildefonso (Segovia), donde nació, y más tarde vinculado a la Real Academia de San Fernando. En esta institución ganó el Premio de Pintura de Primera Clase en el año $1772^{18}$. Hacia 1766 fue pensionado durante veinte años por el infante don Luis (1727-1785), con 200 ducados de vellón anuales, para su formación al lado de Anton Raphael Mengs (1728-1779). A través de su relación con el pintor bohemio comenzó a trabajar para la Real Fábrica de Tapices de Santa Bárbara y, más tarde, en los Reales Sitios. Carlos III le nombró Pintor del Rey en 1783, tomándole juramento el Duque de

${ }^{13}$ Véase el estudio introductorio a la edición contemporánea de Ibid., págs. 24-35.

14 GRAVELOT, H.-F. B. et alii: Iconologiae par figures ou traité complet des allégories, emblèmes.... 4 vols., París, Le Pau, 1791.

15 Sí aparece La Fe, en genérico, como una joven con una hoja de palma arrodillada ante un altar, con una cáliz y la Sagrada Forma resplandeciente sobre la mesa; cfr. Ibid., vol. II, no 51 .

16 Ibid., vol. IV, no 43 (grabado realizado por C. L. Lingée según un dibujo de C. N. Cochin «el Joven»).

17 Cfr. Catálogo de la exposición (Madrid, 2004): Valor y lucimiento. Platería en la Comunidad de Madrid, Madrid, Comunidad de Madrid, 2004, pág. 222, no cat. 89 (estudio a cargo de José Manuel Cruz Valdovinos).

18 Aparece reproducido en VV. AA.: Historia y alegoría: Los concursos de Pintura de La Real Academia de Bellas Artes de San Fernando (1753-1808), Madrid, Academia de Bellas Artes de San Fernando, 1994, págs. 124 y 303. 
Medinaceli como mayordomo mayor de Palacio. Durante este período trabajó a las órdenes de Francisco Bayeu (1734-1795), primero, y más tarde bajo la dirección de Mariano Salvador Maella (1739-1819). En 1793, tras el fallecimiento de Ramón Bayeu (1744-1793), Jacinto Gómez solicitó y obtuvo la plaza de pintor de Cámara. Además de las obras que restaurara para los Reales Sitios, se han conservado algunas pinturas suyas en estos lugares (en San Ildefonso, de donde era oriundo, en Aranjuez y en El Escorial, además de otras documentadas en el Palacio Real) ${ }^{19}$. Probablemente, el encargo para las Comendadoras surgiera en el marco de su actividad como pintor al servicio del Rey, acaso a través del Consejo de Órdenes.

Encontramos en esta pintura bastantes concomitancias con obras de Maella, especialmente en lo que se refiere a la composición y a los tipos representados (fig. 4) $)^{20}$; la obra de Jacinto Gómez participa de la misma sensibilidad academicista que impregna el gusto de su época. También podemos compararla con algunas piezas de la propia producción del artista —lamentablemente no muy conocida-; en el boceto para el techo del oratorio del Palacio de la Granja de San Ildefonso ${ }^{21}$, en el San José con el Niño de la catedral de Palencia ${ }^{22}$ o en una Inmaculada que fue subastada hace unos años ${ }^{23}$ observamos figuras semejantes.

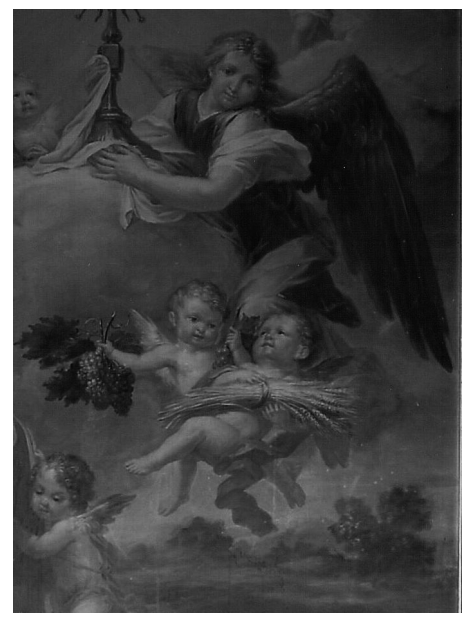

Fig. 4. Ángeles con símbolos eucarísticos, detalle de la Apoteosis de la Eucaristía de Gómez Pastor.

19 El estudio más reciente que conocemos sobre este artista se encuentra en ARNAIZ, J. M.: «Art. cit.», págs. 275-281. Doña Ma Teresa Lavalle-Cobo nos ha comunicado que próximamente publicará un libro dedicado a dicho pintor.

20 Compárese, por ejemplo, con la Virgen de la Almudena reproducida por MORALES Y MARÍN, J. L.: Op. cit., pág. 144, fig. 88. Sobre Maella, resulta imprescindible la investigación monográfica realizada por MANO, J. M. de la: Mariano Salvador Maella: vida y obra de un Pintor de Cámara, Madrid, Universidad Complutense de Madrid, 2008 (tesis doctoral inédita).

${ }_{21}$ Hoy conservado en el Museo del Prado, no cat. 715. Cfr. Museo del Prado. Catálogo de las pinturas, Madrid, Ministerio de Educación y Cultura, 1996, págs. 130 y 751.

22 ARNAIZ, J. M.: «Art. cit.», pág. 278, fig. 33.

23 Subastada en Finarte (Madrid), el 28 de noviembre de 2000, lote $n^{\circ} 9$. Es la que se reproduce en ARNAIZ, J. M.: «Art. cit.», pág. 277, fig. 31; éste publicó otra Inmaculada siguiendo el mismo prototipo en Ibid., pág. 277, fig. 32. 
El marco es el original. Su diseño mixtilíneo (semicircular, flancos rectos y parte inferior quebrada en ángulos rectos) se adapta convenientemente al espacio arquitectónico y a la mesa del altar. Es de una talla primorosa de hojas de acanto entre pequeñas molduras, y todo él está dorado, al gusto de la época.

Además del lienzo, Gómez Pastor podría haberse encargado de pintar el frente del muro, que imita el mármol, pues sabemos que aprendió la técnica del fresco colaborando con Francisco Bayeu; aunque también es probable que hubiese dejado esta tarea menor en manos de algún ayudante.

El conjunto formado por la mesa de altar y el gran lienzo de Jacinto Gómez Pastor aparece coronado por dos Ángeles tenantes con el escudo de la Orden de Santiago realizados en estuco (fig. 5) ${ }^{24}$. Esta pareja de ángeles niños sostienen y flanquean un tondo con la cruz santiaguista rodeada de ramos de laurel dorados, a la manera de una imago clipeata clásica. Dichas figuras se adaptan a la forma curva del arco, por encima del marco que encuadra la pintura. Simulan gravitar, como lo hacen los ángeles de la pintura, con las piernas cruzadas. Uno mira al escudo mientras el otro lo sujeta y mira hacia el espectador - también se observa este recurso en el ángel tenante de la pintura-. Sendos paños cubren púdicamente el sexo de cada uno de ellos, pasando también por el brazo; el trabajo de sus pliegues es sumamente sintético. Las alas están talladas con mayor detalle. Los cabellos aparentan cierto movimiento.

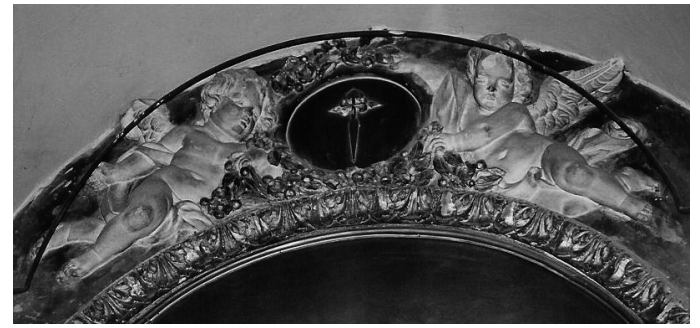

Fig. 5. Roberto o Pedro Michel (atrib.). Ángeles tenantes con el escudo de la Orden de Santiago [E7]. Estucos que decoran el altar del Santísimo Sacramento, en la iglesia de las Comendadoras de Santiago.

A nuestro juicio, su artífice ha de hallarse entre los escultores vinculados a la Real Academia de San Fernando y a las decoraciones cortesanas de la segunda mitad del siglo XVIII. Según hemos explicado en otro lugar, los hermanos franceses Roberto y Pedro Michel (1720-1786 y 1728-1809) serían buenos candidatos para establecer una atribución sólida, por razones estilísticas y por ciertos vínculos

24 E-7. Anónimo madrileño. Hacia 1783. Relieves de estuco parcialmente dorado. Aprox. 80 x $65 \mathrm{~cm}$. cada ángel. Estado de conservación: regular; tienen algunas pérdidas y suciedad generalizada. Emplazamiento: en la capilla occidental de la iglesia, dedicada a la Eucaristía, frente a la reja del coro de religiosas (ubicación original). Bibl.: TAMAYO, A.: Op. cit., pág. 221; SÁNCHEZ RIVERA, J. Á.: «Robert Michel en la iglesia de las Comendadoras de Santiago", Anales del Instituto de Estudios Madrileños, (en prensa). 
profesionales con el cenobio santiaguista, sin olvidar por ello la huella de otros artifices como Manuel Álvarez (1721-1797), Francisco Gutiérrez (1727-1782) o Juan de León (1712-1767), quienes ya habían realizado obras similares para edificios reales e iglesias de Madrid²5.

Finalmente, añadiremos el conocimiento del pago de varios trabajos de carpintería a Felipe Mañero, entre ellos «un dosel guarnecido de damasco con tachuela dorada y cinta el damasco, bara y media», por el cual cobró 76 reales el 11 de mayo de $1799^{26}$. Esta pieza se corresponde perfectamente con un dosel ${ }^{27}$, hoy desmontado, que, según las religiosas, se encontraba por debajo de los estucos -aún se puede observar el hierro curvo que lo sostenía anclado al muro-, cubriendo el lienzo de la Apoteosis de la Eucaristía.

25 Ibid.

${ }^{26}$ El carpintero cobró en aquel momento por la hechura de otros muebles para el convento (un reclinatorio, una mesa, un biombo...), realizados por orden de doña Juana Manso del Águila, prelada del mismo. Muebles que no debían tener un valor especial, a tenor de las cantidades pagadas. AHN, Órdenes Militares, leg. 7.302, «Cuenta y Razón de obra de carpintería...» (11 de mayo de 1799).

27 De estilo neoclásico, presenta una estructura de madera chapada, con decoración de listas de marquetería y tres tachuelas de metal dorado (¿latón?). Esta suerte de entablamento tiene forma mixtilínea, con la parte central curvada hacia fuera. Lo remata una corona de laurel de talla, dorada y blanca, que ha de imitar el trabajo de estuco dorado que adorna el clípeo santiaguista del altar. De la madera cuelga una tela de raso azul, adornada con flecos dorados y pasamanería, que habría de ser realizada posteriormente, en sustitución del «damasco» original. 